\title{
Down-regulation of human FEN-1 gene expression during differentiation of promyelocytic leukemia cells
}

\author{
In-Sook Kim \\ Department of Natural Sciences Chemistry Section, The Catholic University of Korea \\ College of Medicine, Seoul 137-701, Korea; Phone, 82-2-590-1269; Fax, 82-2-592- \\ 7068; E-mail, ikim@cmc.cuk.ac.kr \\ Accepted 9 November 1998
}

Abbreviations: DMSO, dimethyl sulfoxide; FEN-1, flap endo/exonuclease; MF-1, maturation factor-1; PCNA, proliferating cell nuclear antigen; PMSF, phenylmethylsulfonyl fluoride; RA, all-trans retinoic acid; TPA, 12-0tetradecanoylphorbol-13-acetate; XPG, Xeroderma Pigmentosum complementation group G

\begin{abstract}
Flap endo/exonuclease-1 (FEN-1) recognizes 5'-flap DNA structures that have been proposed to be important intermediates in DNA replication, repair and recombination, and cleaves the double strandsingle strand junction of flap substrates. Using an in vitro model system, recent studies have shown that FEN-1 is a necessary enzyme for the removal of RNA primers in Okazaki fragment maturation during lagging strand DNA synthesis. In this report, the FEN1 gene expression was examined during cell cycle and differentiation. Although FEN-1 mRNA and protein could be detected at all stages of the cell cycle, their levels were more elevated in exponentially proliferating cells than in G1 or G2/M-synchronized cells. Moreover, a significant increase of FEN-1 protein was observed when temporarily quiescent fibroblasts were induced to proliferate by serum stimulation. In contrast, the FEN-1 mRNA level showed a sharp decrease in HL-60 cells differentiated by dimethylsulfoxide, all-trans retinoic acid or 12-O-tetradecanoylphorbol-13-acetate. These results demonstrate that the FEN-1 gene expression is up-regulated during entrance into the mitotic cell cycle and downregulated in nongrowing cells, as in the case of differentiated promyelocytic leukemia cells.
\end{abstract}

Keywords: Cell differentiation, FEN-1, Gene expression, HL-60 cells

\section{Introduction}

Flap endo/exonuclease-1 (FEN-1), a structure specific nuclease, cleaves the double strand-single strand junction of 5'-branched DNA, called a DNA flap structure, and also possesses $5^{\prime} \rightarrow 3^{\prime}$ exonuclease activity with a specificity for double stranded DNA containing nick or 5'-recessed ends (Harrington and Lieber, 1994a). It has been proposed that DNA flap structures exist in vivo as intermediates during DNA replication, DNA repair and homologous DNA recombination (Pont-Kingdon et al., 1993; Turchi et al., 1994).

The nucleotide sequence of FEN-1 is highly homologous to the RAD2 gene family such as the human Xeroderma Pigmentosum complementation group G (XPG), S. cerevisiae RAD2, S. cerevisiae YKL510 and S. pombe rad13, which are required for nucleotide excision repair (Prakash et al., 1993; Harrington and Lieber, 1994b; Murray et al., 1994). Therefore, it has been hypothesized that FEN-1 participates in the DNA repair mechanism.

Recently, it has been shown that FEN-1 is the same enzyme as maturation factor-1 (MF-1) (Hiraoka et al., 1995) which is one of the components necessary for SV40 DNA replication in vitro (Waga et al., 1994). In addition, FEN-1 shows significant DNA sequence homology (Shen et al., 1996) and similar enzyme activity (Turchi and Bambara, 1993) to the $5^{\prime} \rightarrow 3^{\prime}$ exonuclease domain in E. coli DNA polymerase I, that also belongs to the structure-specific nucleases family (Lyamichev et al., 1993). A bovine analogue of human FEN-1 has been detected in highly purified fractions of DNA polymerase $\varepsilon$, and is required for Okazaki fragments processing during lagging strand DNA synthesis (Bambara et al., 1997).

Taken together, it has been proposed that FEN-1 is an eukaryotic counterpart to the $5^{\prime} \rightarrow 3^{\prime}$ exonuclease domain in prokaryotic DNA polymerase, and plays an important role in DNA replication, repair and recombination. However, to date there is no study showing the gene expression of FEN-1 in specific cell cycle stages. In this paper, the gene expression of human FEN-1 was analyzed during the cell cycle and cell cycle exit phase using HL-60 cells in different growth conditions.

\section{Materials and Methods}

\section{Materials}

Hydroxyurea, nocodazole, dimethylsulfoxide (DMSO), all-trans retinoic acid (RA), 12-O-tetradecanoylphorbol13-acetate (TPA), phenylmethylsulfonyl fluoride (PMSF), trypsin inhibitor, leupeptin, antipain and propidium iodide were purchased from Sigma Chem. Co. (St. Louis, MO). DNase-free RNase was obtained 
from Boehringer Mannheim (Mannheim, Germany). $\mathrm{Ni}^{2+}$-Sepharose gel was purchased from Invitrogen Co. (Carlsbad, CA). All other chemicals used in the study were of reagent grade.

\section{Cell culture and synchronization}

The HL-60 and NIH-3T3 cells were obtained from American Type Culture Collection (Rockville, MD) and grown in RPMI 1640 medium supplemented with $10 \%$ heatinactivated fetal bovine serum at $37^{\circ} \mathrm{C}$ in a humidified atmosphere of $5 \% \mathrm{CO}_{2}$.

To synchronize cells at the G1 phase, the HL-60 cells were seeded at a density of $1 \times 10^{5} / \mathrm{ml}$ and hydroxyurea was added to a final concentration of $1 \mathrm{mM}$. The cells were then incubated for $12 \mathrm{~h}$ at $37^{\circ} \mathrm{C}$ in $\mathrm{CO}_{2}$-incubator. For preparing $\mathrm{G} 2 / \mathrm{M}$-arrested cells, the cells were treated with $0.1 \mu \mathrm{g} / \mathrm{ml}$ nocodazole for $16 \mathrm{~h}$.

\section{Flow cytometry analysis}

Exponentially proliferating HL-60 cells and cell cyclearrested cells were washed with PBS twice, fixed in cold $70 \%$ ethanol, and stored at $4^{\circ} \mathrm{C}$. After 2 days, the cells were resuspended in $1 \mathrm{ml}$ of PBS containing DNasefree RNase $A(40 \mathrm{u} / \mathrm{ml})$ and propidium iodide $(50 \mu \mathrm{g} / \mathrm{ml})$. Following a 45 min agitated incubation at room temperature, the amount of propidium iodide incorporation was determined using a flow cytometer (Coulter Epics Profile II, Hialeah, FL) (Logan et al., 1995)

\section{Induction of differentiation}

HL-60 cells $\left(1 \times 10^{5} / \mathrm{ml}\right)$ were seeded in a medium containing DMSO $(1.3 \%)$, RA $(1 \mu \mathrm{M})$ or TPA $(100 \mathrm{nM})$, and then cultured at $37^{\circ} \mathrm{C}$ in a $5 \% \mathrm{CO}_{2}$-incubator for 5 days (TPA) or 7 days (DMSO and RA). Differentiation of cells was evaluated by morphological changes.

\section{Preparation of anti-FEN-1 antibody}

For protein overexpression, the DE3 cells ( $E$. coli strain BL21) transformed by $\mathrm{pET}-\mathrm{FCH}$ plasmid containing human FEN-1 cDNA were kindly donated by Dr. Park (Los Alamos Natl. Lab., NM). The recombinant FEN-1 protein was purified by passing the supernatant of the DE3 cell lysates over a $\mathrm{Ni}^{2+}$-Sepharose column under nondenaturing conditions.

The antibody for western blot analysis was prepared by immunizing rabbits with the purified recombinant hFEN-1 protein.

\section{Western blot analysis}

The synchronized cells were washed with PBS twice, and then lysed in RIPA buffer (50 mM Tris, $150 \mathrm{mM}$ $\mathrm{NaCl}, 1 \% \mathrm{NP}-40,0.5 \%$ sodium deoxycholate, $0.1 \%$ SDS, $1 \mathrm{mM}$ PMSF, $100 \mu \mathrm{g} / \mathrm{ml}$ trypsin inhibitor, $50 \mu \mathrm{M}$ leupeptin, $100 \mu \mathrm{M}$ antipain; $\mathrm{pH}$ 8.0) . After determining protein concent-ration of each lysate, equal amounts of the samples were loaded on a $12.5 \%$ SDS-polyacrylamide gel. Proteins were transferred to a nitrocellulose membrane and analyzed with the anti-hFEN-1 antibody using an enhanced chemiluminescence detection kit (Amersham, Bucking-hamshire, U.K.).

\section{Northern blot analysis}

Total cellular RNAs were isolated from HL-60 cells treated with or without various reagents. six $\mu \mathrm{g}$ of the each RNA sample were electrophoresed on $1 \%$ agarose-formaldehyde gel and transferred to a nylon membrane. FEN-1 mRNA was analyzed by the DIG chemiluminescence detection method according to the procedure recommended by the manufacturer (Boehringer Mannheim, Mannheim, Germany). The probes incorporated with DIG-11-dUTP were prepared by PCR amplification (606 - 940 bp region of human FEN-1 cDNA).

\section{Results and Discussion}

\section{Gene expression of FEN-1 during cell proliferation}

It has been shown that FEN-1 is an important component for DNA replication (Bambara et al., 1997), and that several proteins acting in DNA replication, such as DNA polymerase $\alpha$, proliferating cell nuclear antigen (PCNA), and DNA ligase, are inducible during cell proliferation (Wahl et al., 1988; Montecucco et al., 1992; Moore and Wang, 1994). In order to examine whether FEN-1 could also be induced during cell proliferation, FEN-1 gene expression was analyzed in specific cell cycle stages and during cell cycle exit.

For synchronizing in $\mathrm{G} 1$ and $\mathrm{G} 2 / \mathrm{M}$ phases, HL-60 promyelocytic leukemia cells were incubated with $1 \mathrm{mM}$ of hydroxyurea for $12 \mathrm{~h}$ and $0.1 \mu \mathrm{g} / \mathrm{ml}$ of nocodazole for $16 \mathrm{~h}$, respectively. After incubation, the DNA contents of the cells were analyzed using a flow cytometer. As shown in Figure $1 \mathrm{~A}$, more than $80 \%$ of the hydroxyurea-treated cells arrested at $\mathrm{G} 1$ and about $70 \%$ of the nocodazoltreated cells arrested at G2/M. When the HL-60 cells were incubated with $0.1 \mu \mathrm{g} / \mathrm{ml}$ of nocodazole for $16 \mathrm{~h}$, some cells died because of the toxicity of this reagent. It is likely that the cell population having a low DNA content shown in Figure 1Ac corresponds to the dead cells. As it is difficult to get cells in the $S$ phase only, exponentially growing HL-60 cells (log-phase cells) were used instead of cells synchronized in the $S$ phase (cells synthesizing DNA).

Total RNAs were isolated from G1 and G2/M-arrested HL-60 cells as well as exponentially growing cells. The FEN-1 mRNA level was checked by northern blot analysis using a human FEN-1 specific probe labeled with DIG. Not only log-phase HL-60 cells, but also G1 or G2/M- 
(A)
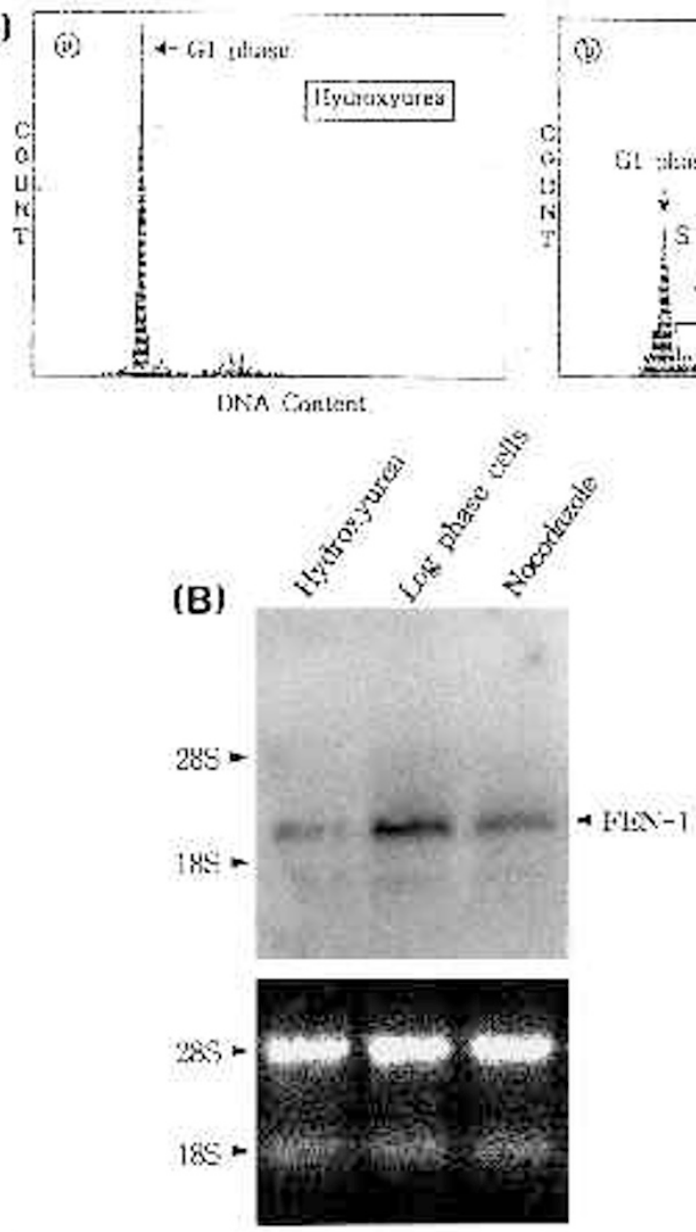

arrested cells exhibited FEN-1 gene expression, but the mRNA level was higher in exponentially growing cells than in growth-arrested cells (Figure 1B). The protein levels in growing and temporarily growth-arrested cells showed similar patterns to the mRNA levels (Figure 1C).

After NIH-3T3 mouse fibroblast cells were growtharrested at the $\mathrm{G} 1$ stage by serum starvation, the cells reentered the mitotic cell cycle following serum stimulation. As shown in Figure 2, a sharp increase of the FEN-1 protein resulted from the induction of entry into the $S$ phase of G1-arrested NIH-3T3 cell.

These results show that FEN-1 is up-regulated during cell proliferation, and shows a similar pattern to other DNA replication proteins, such as DNA polymerase $\alpha$ and DNA ligase, which are also inducible in cell proliferation (Wahl et al., 1988; Montecucco et al., 1992; Moore and Wang, 1994).

\section{Induction of differentiation of HL-60 cells}

It was discussed as to whether FEN-1 gene expression could be down-regulated in non-growing cells which had exited the cell cycle permanently. It has been well estab-

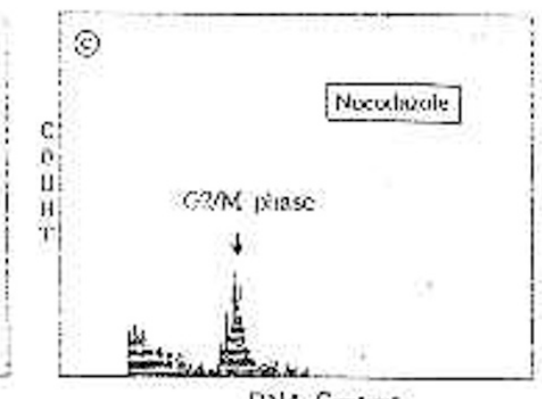

1)NA Cinturil
D.N Cxitunt
(C)

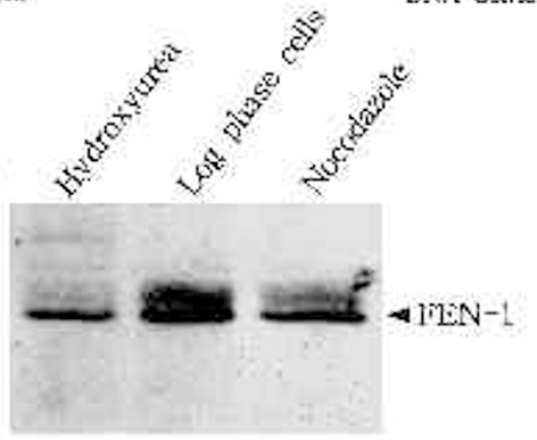

Figure 1. Gene expression of human FEN-1 during cell cycle. (A) Flow cytometry of cell cycle-synchronized HL-60 cells. Exponentially proliferating HL-60 cells (b) were synchronized in $\mathrm{G} 1$ by treating with $1 \mathrm{mM}$ hydroxyurea for $12 \mathrm{~h}$ (@), and in G2/M with $0.1 \mu \mathrm{g} / \mathrm{ml}$ nocodazole for $16 \mathrm{~h}$ (C). (B) Northern blot analysis. After synchronization, total RNAs were prepared from the cells in different cell cycle stages, and $6 \mu \mathrm{g}$ RNA of each preparation were loaded on $1 \%$ agarose gel. DIG-labeled PCR product of human FEN-1 gene (606-964 bp region) was used as a probe, and equal amounts of RNA loaded on each lane were determined by EtBr staining. (C) Western blot analysis of human FEN-1.

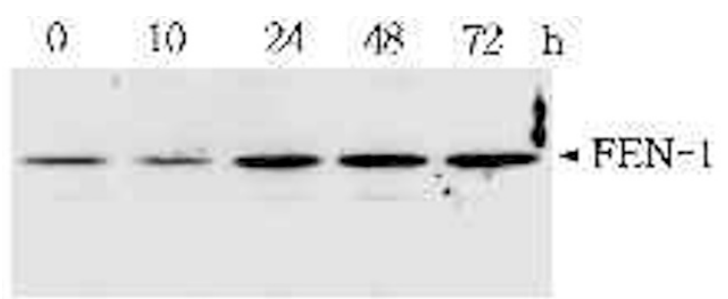

Figure 2. Up-regulation of FEN-1 protein synthesis in mitotic cells. A confluent monolayer of $\mathrm{NIH} 3 \mathrm{~T} 3$ cells were starved for 2 days in a serum-free medium. Then the cells were stimulated for the indicated times in the presence of $10 \%$ serum in order to reenter the mitotic cell cycle. The FEN-1 protein levels were analyzed by immunoblotting.

lished that HL-60 promyelocytic leukemia cells could be induced through terminal differentiation into granulocytes or macrophages by DMSO, RA or TPA, respectively, and so $\mathrm{HL}-60$ cells were incubated with $1.3 \%$ DMSO or $1 \mu \mathrm{M}$ RA for 7 days, or with 100 nM TPA for 5 days in order to prepare nongrowing human leukemia cells. After incubation, cell differentiation was evaluated by observing morphological changes of the cells. Nuclei of DMSO- 
(A)

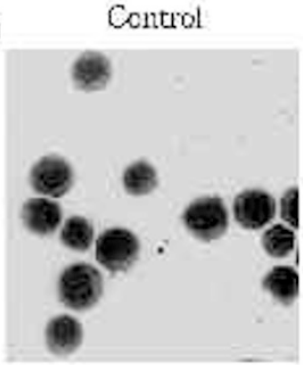

RA

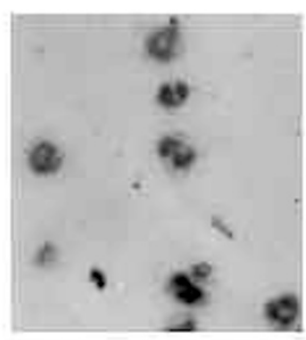

DMiso

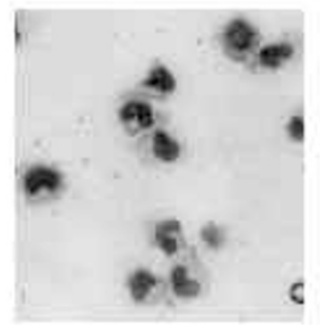

TPA

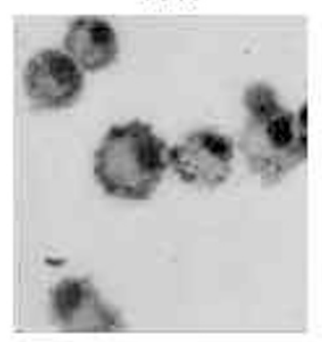

(B)
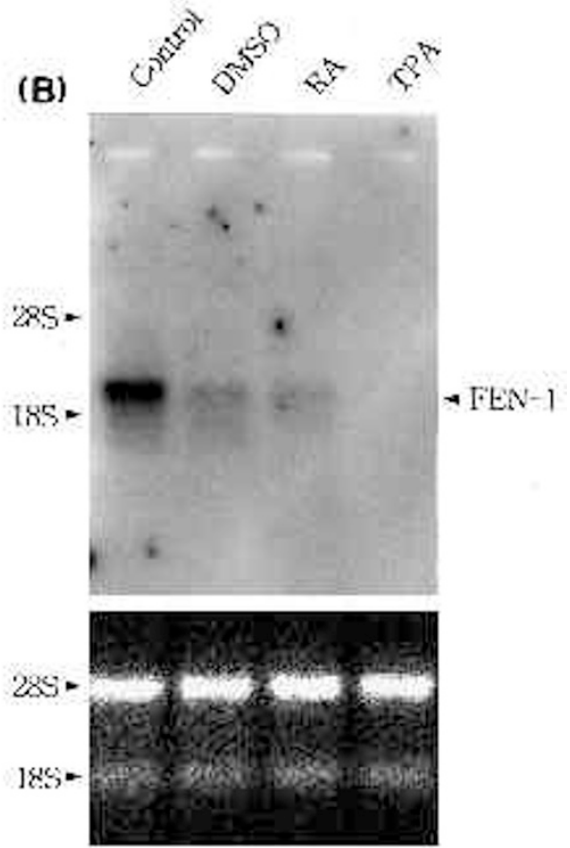

Figure 3. Down-regulation of human FEN-1 gene expression during cell differentiation. HL-60 cells $\left(1 \times 10^{5} / \mathrm{ml}\right)$ were treated with $1.3 \%$ DMSO or $1 \mu \mathrm{M}$ RA for 7 days, or with $100 \mathrm{nM}$ TPA for 5 days. (A) To evaluate cell differentiation, the cells incubated with various agents were stained with Giemsa solution and photographed (× 400). (B) Northern blot analysis was performed for detection of FEN-1 mRNA levels in the differentiated $\mathrm{HL}-60$ cells. and RA-treated cells were similar to that of granulocytes showing bending and segregated nuclei, while TPA-treated cells had a decreased nucleus/cytosol ratio contrast compared to untreated control cells in Giemsa staining (Figure 3A). The TPA-treated cells also adhered to the bottom of the culture dish. These results indicate that HL-60 cells were well differentiated into granulocytes or macrophages by DMSO, RA, or TPA.

\section{Down-regulation of FEN-1 gene expression in differentiated $\mathrm{HL}-60$ cells}

Human FEN-1 gene expression in differentiated HL-60 cells was analyzed by the northern blot method. As shown in Figure 3B, HL-60 cells differentiated into granulocytes by DMSO and RA showed a remarkable decline in FEN-1 gene expression, $30 \%$ and $20 \%$ respectively, to the control mRNA level. Specifically, FEN-1 mRNA was not detectable in HL-60 cells treated with TPA for 5 days. These results demonstrate that human FEN-1 gene expression is substantially down-regulated at the mRNA level during cell differentiation, suggesting that human FEN-1 parti-cipates in cell proliferation.

In this study, to identify FEN-1 as a DNA replication protein, human FEN-1 gene expression was examined in actively growing and nongrowing human promyelocytic leukemia cells. Data indicates that human FEN-1 gene is up-regulated during entry into the $S$ phase of G1-arrested cells, and down-regulated in nongrowing cells.

Also, recent studies have demonstrated that FEN-1 is an important enzyme for DNA replication. i.e., i)
Mutant cells lacking in yeast FEN-1 gene showed deficient cell growth (Johnson et al., 1995). ii) Yeast FEN-1 interacted with a replicative helicase (Budd and Campbell, 1997) as well as PCNA (Li et al., 1995) which is the accessory factor for DNA polymerases $\delta$ and $\varepsilon$. iii) Calf FEN-1 homo-logy was copurified with calf DNA polymerase $\varepsilon$ (Bambara et al., 1997). iv) Bovine FEN-1 acted in the removal of RNA primer during Okazaki fragment maturation (Bambara et al., 1997).

Together with data from these experiments and other researchers' data, it seems likely that FEN-1 gene expression is induced during cell proliferation to play a role in DNA replication. These facts suggest that FEN-1 may be applied as a useful new tumor marker, the work is now in progress.

\section{Acknowledgement}

I thank Dr. M.S. Park (Life Sciences Division, Los Alamos National Laboratory, New Mexico) for his generous gift of human FEN-1 cDNA.

\section{References}

Bambara, R. A., Murante, R. S. and Henricksen, L. A. (1997) Enzymes and reactions at the eukaryotic DNA replication fork. J. Biol. Chem. 272: 4647-4650

Budd, M. E. and Campbell, J. L. (1997) A yeast replicative helicase, Dna2 helicase, interacts with yeast FEN-1 nuclease in carrying out its essential function. Mol. Cell. Biol. 17: $2136-2142$

Harrington J. J. and Lieber, M. R. (1994a) The characterization of a mam-malian DNA 
structure-specific endonuclease. EMBO J. 13: 1235-1246

Harrington J. J. and Lieber, M. R. (1994b) Functional domains within FEN-1 and RAD2 define a family of structure-specific endonucleases: implications for nucleotide excision repair. Genes and Dev. 8: 1344-1355

Hiraoka, L. R., Harrington, J. J., Gerhard, D. S., Lieber, M. R. and Hsieh, C.-L. (1995) Sequence of human FEN-1, a structure-specific endonuclease, and chromosomal localization of the gene (FEN1) in mouse and human. Genomics 25: 220-225

Johnson, R. E., Kovvali, G. K., Prakash, L. and Prakash, S. (1995) Requirement of the yeast RTH1 5'to 3 ' exonuclease for the stability of simple repetitive DNA. Science 269 : 238-239

Li, X., Li, J., Harrington, J., Lieger, M. R. and Burgers, P. M. J. (1995) Lagging strand DNA synthesis at the eukaryotic replication fork involves binding and stimulation of FEN-1 by proliferating cell nuclear antigen. J. Biol. Chem. 270: 22109-22112

Logan, T. J., Evans, D. L., Mercer, W. E., Bjornsti, M.-A. and Hall, D. J. (1995) Expression of a deletion mutant of the E2F1 transcription factor in fibroblasts lengthens $S$ phase and increases sensitivity to S phase-specific toxins. Cancer Res. 55: 28832891

Lyamichev, V., Brow, M. A. D. and Dahlberg, J. E. (1993) Structure-specific endonucleolytic cleavage of nucleic acids by eubacterial DNA polymerases. Science 260: 778-783

Montecucco, L., Biamonti, G., Savini, E., Focher, F., Spadari, S. and Ciarrocchi, L. (1992) DNA ligase I gene expression during differentiation and cell proliferation. Nucleic Acids Res. 20: 6209-6214

Moore, A. L. and Wang, T. S.-F. (1994) Down-regulation of genes encoding DNA replication proteins during cell cycle exit. Cell Growth and Differen-tiation 5: 485-494

Murray, J. M., Tavassoli, M., Al-Harithy, R., Sheldrick, K. S., Lehmann, A. R., Carr, A. M. and Watts, F. Z. (1994) Structural and functional conser-vation of the human homolog of the Schizosaccharomyces pombe rad2 gene, which is required for chromosome segregation and recovery from DNA damage. Mol. Cellul. Biol. 14: 4878-4888

Pont-Kingdon, G., Dawson, R. J. and Carroll, D. (1993) Intermediates in extrachromosomal homologous recombination in Xenopus laevis oocytes: characterization by electron microscopy. EMBO J. 12: 23-24

Prakash, S., Sung, P. and Prakash, L. (1993) DNA repair genes and proteins of Saccharomyces cerevisiae. Annu. Rev. Genet. 27: 33-70

Shen, B., Nolan, J. P., Sklar, L. A. and Park, M. S. (1996) Essential amino-acids for substrate binding and catalysis of human flap endonuclease 1. J. Biol. Chem. 271: 9173-9176

Turchi, J. J. and Bambara, R. A. (1993) Completion of mammalian lagging strand DNA replication using purified proteins. J. Biol. Chem. 268: 15136-15141

Turchi, J. J., Huang, L., Murante, R. S., Kim, Y and Bambara, R. A. (1994) Enzymatic completion of mammalian lagging-strand DNA replication. Proc. Natt. Acad. Sci. USA 91: 9803-9807

Waga, S., Bauer, G. and Stillman, B. (1994) Reconstitution of complete SV40 DNA replication with purified replication factors. J. Biol. Chem. 269: 10923-10934

Wahl, A. F., Geis, A. M., Spain, B. H., Wong, S. W., Korn, D. and Wang, T. S.-F. (1988) Gene expression of human DNA polymerase $\alpha$ during cell proliferation and the cell cycle. Mol. Cell. Biol. 8: 5016-5025 